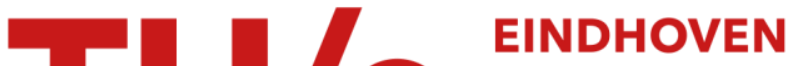 UNIVERSITY OF TECHNOLOGY
}

\section{High-power three-port three-phase bidirectional DC-DC converter}

\section{Citation for published version (APA):}

Tao, H., Duarte, J. L., \& Hendrix, M. A. M. (2007). High-power three-port three-phase bidirectional DC-DC converter. In Proceedings of the 42th Industry Application Society conference and annual meeting (IAS'07), 2327 September 2007, New Orleans, USA (pp. 1-8). Institute of Electrical and Electronics Engineers.

\section{Document status and date:}

Published: 01/01/2007

\section{Document Version:}

Publisher's PDF, also known as Version of Record (includes final page, issue and volume numbers)

\section{Please check the document version of this publication:}

- A submitted manuscript is the version of the article upon submission and before peer-review. There can be important differences between the submitted version and the official published version of record. People interested in the research are advised to contact the author for the final version of the publication, or visit the $\mathrm{DOI}$ to the publisher's website.

- The final author version and the galley proof are versions of the publication after peer review.

- The final published version features the final layout of the paper including the volume, issue and page numbers.

Link to publication

\section{General rights}

Copyright and moral rights for the publications made accessible in the public portal are retained by the authors and/or other copyright owners and it is a condition of accessing publications that users recognise and abide by the legal requirements associated with these rights.

- Users may download and print one copy of any publication from the public portal for the purpose of private study or research.

- You may not further distribute the material or use it for any profit-making activity or commercial gain

- You may freely distribute the URL identifying the publication in the public portal.

If the publication is distributed under the terms of Article $25 \mathrm{fa}$ of the Dutch Copyright Act, indicated by the "Taverne" license above, please follow below link for the End User Agreement:

www.tue.nl/taverne

Take down policy

If you believe that this document breaches copyright please contact us at:

openaccess@tue.nl

providing details and we will investigate your claim. 


\title{
High-Power Three-Port Three-Phase Bidirectional DC-DC Converter
}

\author{
Haimin Tao, Jorge L. Duarte, Marcel A.M. Hendrix \\ Group of Electromechanics and Power Electronics \\ Eindhoven University of Technology \\ 5600 MB Eindhoven, The Netherlands \\ Email: h.tao@tue.nl
}

\begin{abstract}
This paper proposes a three-port three-phase bidirectional dc-dc converter suitable for high-power applications. The converter combines a slow primary source and a fast storage to power a common load (e.g., an inverter). Since this type of system is gaining popularity in sustainable energy generation systems and electrical vehicles, the proposed topology is of practical interest. The proposed converter consists of three high-frequency inverter stages operating in a six-step mode, and a high-frequency three-port three-phase symmetrical transformer. The converter provides galvanic isolation and supports bidirectional power flow for all the three ports. An arbitrary power flow profile in the system can be achieved by phase shifting the three inverter stages. Thanks to the three-phase structure, the current handling capability of the circuit is larger and the ripple currents at the dc sides are much lower owing to the interleaving effect of the threephase, and thus the VA rating of the filter capacitors is much lower. The operating principle and, in particular, the transformer design which is based on conventionally and coaxially wound structures are presented. Circuit simulation results are included to verify the proposed converter topology and the dual-PI-loop control strategy.
\end{abstract}

\section{INTRODUCTION}

In the past decades, traditional power converter topologies have been evolving in various directions, for example, from single-phase to multiphase interleaving, and from two-level to multilevel. Nowadays, most dc-dc power converters deal with single-input and single-output. Recently, attention has been paid to multiport converters [1]. Power conversion systems which combine a slow primary source with a fast storage to power a common load, which could be downstream converters (e.g., an inverter), are gaining popularity in sustainable energy generation [2], [3] and electrical vehicles [4].

Alternative energy generators like fuel cells have slow dynamics and quite specific dc voltage and current characteristics. Furthermore, energy supplied by renewable sources such as solar and wind energy has an intermittent nature, which necessitates a battery-type storage capable of long-term energy buffering. For electrical vehicle applications, transient energy storage is required to cope with the acceleration and braking of vehicles. A three-port energy management system accommodates a primary source and a storage and combines their advantages automatically, while utilizing a single power conversion stage to interface the three power ports. Having the two energy inputs, the instantaneous power can be redistributed in the system in a controlled manner. The storage acts as

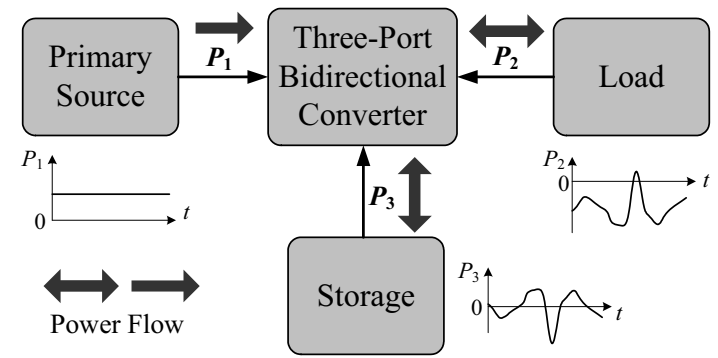

Fig. 1. A three-port energy flow management system.

a power filter to smooth the power flow of the primary source, as shown in Fig. 1.

A second advantage of using such a system is that the primary source only needs to be sized according to the average power consumed by the load for a specific application, not necessarily to the peak power. Such operation would avoid oversizing of the primary source and is economically beneficial. Moreover, with the auxiliary storage, not only can the system dynamics be improved, but also the storage can serve as a backup energy source in the event of a main source failure.

In this regard, a few attempts have been made to explore dc-dc topologies suitable for multiple sources and/or storage elements [1], [2], [3], [4], [5], [6], [7], [8]. However, most of them are intended for medium- and low-power applications.

In this paper, a three-port three-phase converter topology suitable for power management is proposed, and its potential for high-power applications is investigated. The converter is a direct extension of the single-phase version of the threeport converter in [6] and [8]. It is shown that the three-phase configuration enhances the current rating of the system and thus the power rating. The converter is promising for electrical vehicles (e.g., fuel cell/battery cars) and electricity generation systems. The three-phase concept has also been recognized in [5] for a multiple-input converter which can be regarded as an extension of the single-phase topology in [3] that uses a combination of a dc-link and magnetic-coupling to interface multiple power ports. The system modeling, operation principle, control strategy, transformer design, and simulation results are presented in the following sections. 


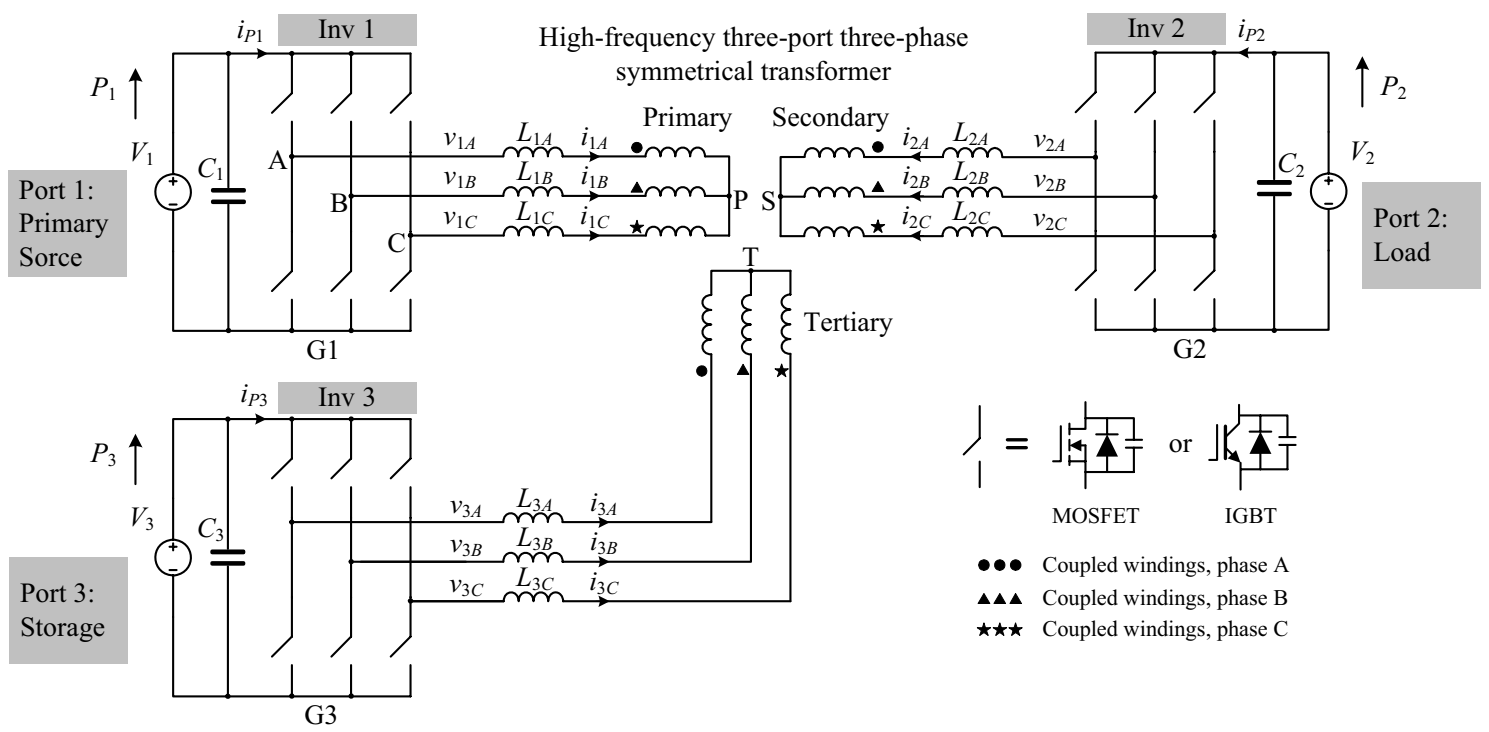

Fig. 2. Topology of the proposed high-power three-port three-phase triple-active-bridge (TAB) bidirectional dc-dc converter.

\section{Three-Port Three-Phase TOPOlOgy}

The three-port triple-active-bridge (TAB) topology has been proposed for a fuel cell system for home applications rated at a maximum power of $1 \mathrm{~kW} \mathrm{[7],} \mathrm{[9]} \mathrm{and} 3.5 \mathrm{~kW}[10]$. To extend the topology towards high-power applications, the standard way is to replace the single-phase bridge with a threephase bridge, which enables higher current handling ability. The resulting converter topology is shown in Fig. 2. The threephase concept used in the dual-active-bridge (DAB) converter [11] is applied to the TAB converter in this paper. As shown, the circuit consists of three inverter stages operating in a sixstep mode with controlled phase shifts. The three bridges are interconnected by a three-port three-phase symmetrical transformer, and the inductors in the circuit represent the leakage inductance of the transformer (and external inductors if necessary). The transformer can be either in Y-Y or in $\Delta-\Delta$ connection. Note that coupling of the windings is between the ports and there is no interphase coupling. As indicated in the figure, windings marked with the same symbol are coupled.

The major advantage of the three-phase version is the much lower VA rating of the filter capacitors. Thanks to the nature of the symmetry, the current stress of the switching device is significantly reduced compared to the single-phase version. As the current through the transformer windings is much more sinusoidal than in the single-phase situation (this is shown in the simulation section), there are less high frequency losses in the transformer. The proposed converter has the potential for high-power applications (say, tens of kilowatts). The operating principle is very similar to the single-phase version. In addition to galvanic isolation, a major advantage of this converter is the ease of matching the different voltage levels in the overall system. The leakage inductances of the transformer are an integral part of the circuit. With reference to the primary side, each bridge generates a high-frequency six-step mode voltage with a controlled phase angle. The control scheme aims to regulate the output voltage and power of the primary source simultaneously, using two phase shifts as control variables. The storage supplies/absorbs the transient power difference between the load and the primary source. This is an automatic system, matching the variations of the power drawn by the load while the power of the primary source is kept at a constant level.

\section{ThreE-Port System MOdeling}

\section{A. $\Delta$-Model Representation}

The power flow in the three-port system has been extensively investigated in [2] and [8]. Since no interphase coupling exists in the system, one can analyze the circuit based on the per-phase model. For phase A, the circuit model shown in Fig. 3(a) can be viewed as a network of inductors driven by controlled voltage sources that are phase-shifted with respect to each other. The controlled phase displacements impose the power flow between the ports. Fig. 3(b) illustrates the modeling approach based on a $\Delta$-model equivalent transformer representation [2]. The $\Delta$-model facilitates the system's analysis, and simple formulas allow converting the parameters from a T-model to the $\Delta$-model description [2].

Let us set the primary side as the reference for the phase shift, and denote the phase angles of the load side and storage side as $\varphi_{12}$ and $\varphi_{13}$, respectively (see Fig. 4). According to the definitions in Fig. 3(b), for a lossless system the power flow in the system can be described as

$$
\begin{aligned}
& P_{1 A}=P_{12 A}-P_{31 A} \\
& P_{2 A}=P_{23 A}-P_{12 A} \\
& P_{3 A}=P_{31 A}-P_{23 A} \\
& P_{1 A}+P_{2 A}+P_{3 A}=0
\end{aligned}
$$



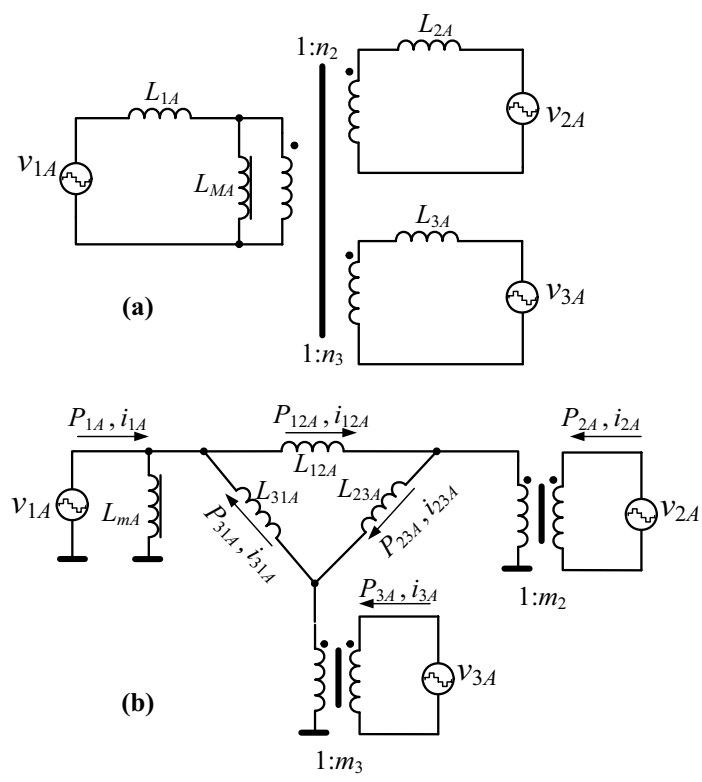

Fig. 3. T-model (a) and $\Delta$-model (b) representation of the three-port transformer and inductors netwerk (per-phase model: phase A).

where $P_{1 A}, P_{2 A}, P_{3 A}$ are the powers delivered by the primary source, load and storage through phase A, respectively. A positive value means supplying the power and a negative value suggests consuming the power. Note that for a lossless system, we have $P_{3 A}=-P_{1 A}-P_{2 A}$; therefore $P_{3 A}$ is redundant. The same model can be applied to phase B and C. Obviously, the total power of the port is the sum of the power through each phase:

$$
\begin{aligned}
& P_{1}=P_{1 A}+P_{1 B}+P_{1 C} \\
& P_{2}=P_{2 A}+P_{2 B}+P_{2 C} \\
& P_{3}=P_{3 A}+P_{3 B}+P_{3 C} .
\end{aligned}
$$

Again, $P_{3}$ is redundant because $P_{3}=-P_{1}-P_{2}$.

The average power consumed by the load over a typical operating cycle shall be equal to the power delivered by the primary source. The storage port thereby functions as an external leveling device, smoothing out the fluctuation in the instantaneous power drawn by the load port.

Owing to symmetry, an analytical expression of the current can be derived [11]. By integrating the product of voltage and current with respect to time over one cycle, the average power transferred between the two ports in the six-step wave mode, taking bidirectional power flow into consideration, is calculated to be

for $0 \leq|\varphi| \leq \pi / 3$ :

$$
P=\frac{V_{a} V_{b}}{m \omega L} \varphi\left(\frac{2}{3}-\frac{|\varphi|}{2 \pi}\right)
$$

and for $\pi / 3 \leq|\varphi| \leq 2 \pi / 3$ :

$$
P=\frac{V_{a} V_{b}}{m \omega L} \varphi\left(1-\frac{|\varphi|}{\pi}-\frac{\pi}{18|\varphi|}\right)
$$

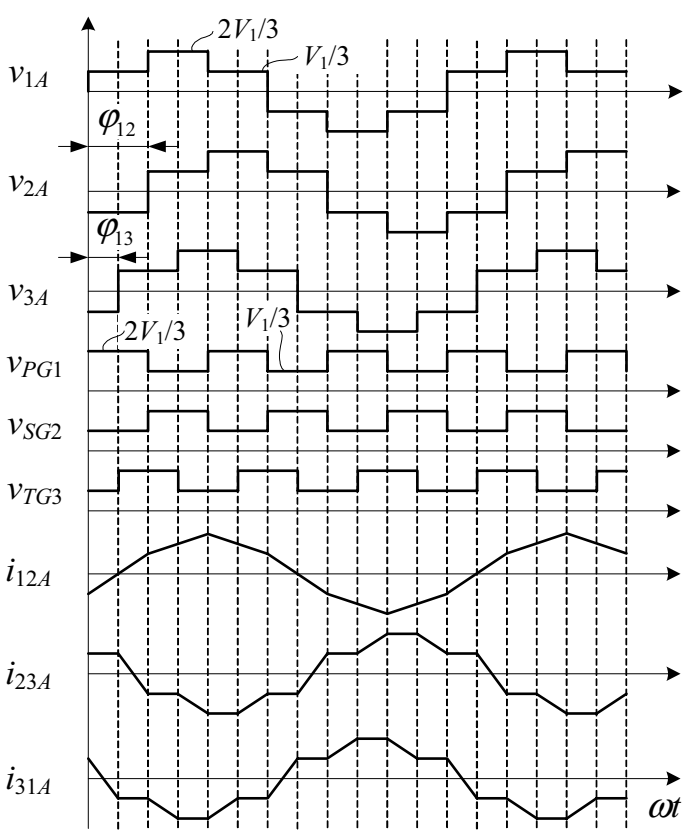

Fig. 4. Idealized operating waveforms (phase A) of the proposed three-port three-phase TAB converter at $\varphi_{12}=\pi / 3$ and $\varphi_{13}=\pi / 6$.

where $\omega=2 \pi f_{s}$ ( $f_{s}$ is the switching frequency); $V_{a}$ and $V_{b}$ are the dc voltages of the ports; $\varphi$ denotes the phase shift (in radians) between the two ports; $L$ represents the equivalent inductance between the two ports; and $m$ is the equivalent transformer turns ratio between the two ports [2] (if the magnetizing inductance is neglected, $m$ is equal to the physical turns ratio $n$ in the T-model.) The maximum power flow occurs at $\varphi= \pm \pi / 2$. To illustrate the operation of the converter, some ideal operating waveforms are shown in Fig. 4, according to the model in Fig. 3(b).

\section{B. First Harmonic Approach}

Since the system can be regarded as voltage sources interconnected through inductors, similar to the parallel operation of grid-frequency inverters where the active power control is achieved by controlling the phase displacement between the inverters, the three-port system can be treated like such a nanoscale grid. The difference, however, is that this system operates at a much higher frequency (e.g., $100 \mathrm{kHz}$ ) than the conventional grid frequency.

Let us define the switching function $S_{x}=1$ when the upper switch is ON and $S_{x}=0$ when the lower switch is ON. Then, as an example, the primary port can be modeled as (referring to the definitions in Fig. 2)

$$
\begin{aligned}
& S_{1 A} V_{1}=\left(v_{1 A}+v_{P G 1}\right) \\
& S_{1 B} V_{1}=\left(v_{1 B}+v_{P G 1}\right) \\
& S_{1 C} V_{1}=\left(v_{1 C}+v_{P G 1}\right)
\end{aligned}
$$

where $V_{1}$ is the dc voltage of the port, $v_{1 A}, v_{1 B}$ and $v_{1 C}$ are the phase-to-neutral voltages, and $v_{P G 1}$ is the neutral (P) to 


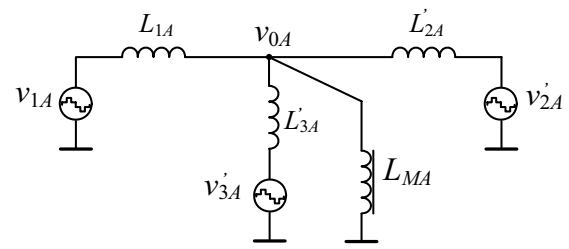

Fig. 5. Primary referred per-phase model of the system (phase A).

ground (G1, the negative terminal of the source) voltage. Since each inverter is a perfectly balanced three-phase system, we have

$$
v_{1 A}+v_{1 B}+v_{1 C}=0
$$

The voltage $v_{P G 1}$ pulsates between $V_{1} / 3$ and $2 V_{1} / 3$ as depicted in Fig. 4.

Fig. 5 shows the per-phase model of the converter when referred to the primary. The place where the magnetizing inductance is connected can be regarded as the connecting point. Assume that the magnetizing inductance is much larger than the leakage inductance. Fig. 6 shows a simplified three-phase model which is analogous to the parallel operation model of grid-frequency inverters. The voltage at the connecting point can be calculated by superposition, which gives, for instance, for phase A:

$$
v_{0 A}=\frac{v_{1 A} L_{2 A}^{\prime} L_{3 A}^{\prime}+v_{2 A}^{\prime} L_{1 A} L_{3 A}^{\prime}+v_{3 A}^{\prime} L_{1 A} L_{2 A}^{\prime}}{L_{1 A} L_{2 A}^{\prime}+L_{1 A} L_{3 A}^{\prime}+L_{2 A}^{\prime} L_{3 A}^{\prime}}
$$

where $L_{2 A}^{\prime}, L_{3 A}^{\prime}, v_{2 A}^{\prime}$ and $v_{3 A}^{\prime}$ represent the primary-referred values of $L_{2 A}, L_{3 A}, v_{2 A}$ and $v_{3 A}$, respectively. Since $v_{0 A}$ is neither accessible nor measurable, it can only be determined by the status of $v_{1 A}, v_{2 A}^{\prime}$ and $v_{3 A}^{\prime}$. For a symmetrical system (i.e., $L_{1 A}=L_{2 A}^{\prime}=L_{3 A}^{\prime}$ ), we have

$$
v_{0 A}=\left(v_{1 A}+v_{2 A}^{\prime}+v_{3 A}^{\prime}\right) / 3 .
$$

With $v_{0 A}$, the power injected into the transformer can simply be given by the familiar equation for the active power control, e.g., for phase A of the primary port

$$
P_{1 A}=\frac{U_{0 A} U_{1 A}}{\omega L_{1 A}} \sin \left(\varphi_{01}\right)
$$

where $\varphi_{01}$ is the phase displacement between $v_{0 A}$ and $v_{1 A}$, and $U_{0 A}$ and $U_{1 A}$ are the amplitudes of the fundamental components of $v_{0 A}$ and $v_{1 A}$, respectively.

The power flow in the three-port system is mainly determined by the fundamental components. This is an acceptable approximation and the error is within 10\% [11]. Therefore, the first harmonic model may be used to estimate the power flow.

\section{Symmetrical TRANSFORMER DESIGN}

The main challenge of the proposed high-power threephase three-port converter is the design of the three-phase symmetrical transformer. It is important to keep the symmetry of the leakage inductances. Otherwise, the current (transferred

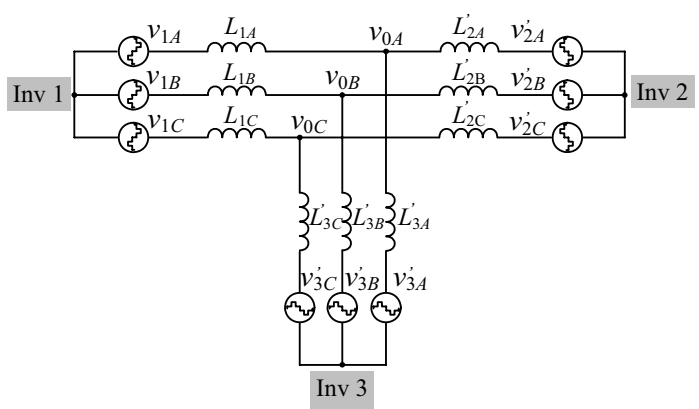

Fig. 6. Simplified three-phase model of the converter.
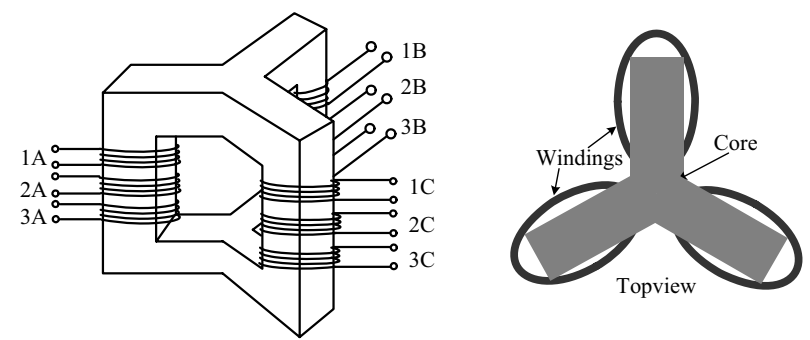

Fig. 7. Conventionally wound three-port three-phase spatially symmetrical transformer.

power) will not be equal for the three phases. The transformer construction may be necessary to be physically symmetrical in order to have an identical leakage inductance in each phase. Otherwise, the external inductances should be adjusted to achieve an equal per-phase leakage inductance.

Basically, there are two ways to wind a transformer: conventionally and coaxially. A conventional winding technique for designing the three-phase symmetrical transformer for a twoport converter has been proposed in [11]. The designed spatial three-phase symmetrical transformer can easily be extended to the three-port version as illustrated in Fig. 7. However, suitable high-frequency core shapes are commercially unavailable. Note that for a simple solution it would be possible to design the transformer as three separated subtransformers since there is no interphase coupling; however this results in a higher transformer core loss, because the flux canceling effect does not apply (the sum of the three phase fluxes equals zero).

Coaxial winding techniques are commonly used in radiofrequency transformers. Fig. 8 shows the structure of a coaxially wound transformer. This technique offers a feasible solution to contain the leakage flux within the inter-winding space and thus prevents the core from being saturated locally [12]. As a result, the core and copper losses are lower, and localized heating is avoided [12]. Furthermore, from a mechanics point of view, this technique offers reduced forces within the transformer and a robust construction. In [12], it has been demonstrated that coaxial windings can lead to low loss, low leakage inductance power transformers in high-frequency softswitched dc-dc and resonant converters. Some of the important loss aspects such as the influence of skin effect on winding 


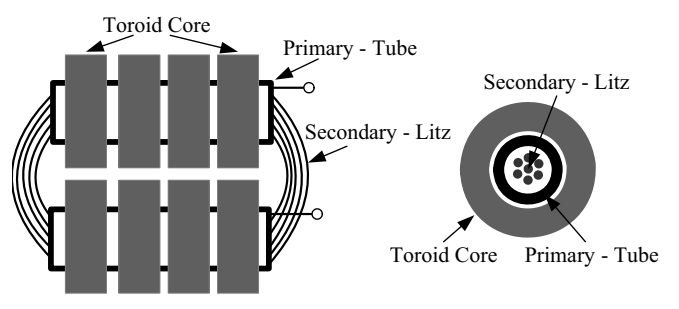

Fig. 8. Coaxially wound transformer.

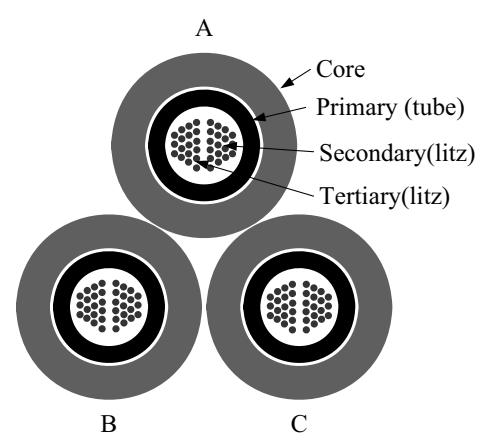

Fig. 9. Coaxially wound three-port three-phase symmetrical transformer.

resistance, the variation of core loss caused by non-uniform core flux density, and the choice of the principle dimensions and aspect ratios for maximum efficiency were examined in [13]. Moreover, it is also possible for the primary to have multiple turns [14]. Coaxial winding techniques therefore provide a viable method for the construction of the converter transformer.

Fig. 9 shows the schematic of the proposed coaxially wound three-port three-phase transformer. The primary of each phase consists of a straight tube of circular cross section. The star point is realized by shorting the tubes at one end. Toroidal cores are slipped over each tube to form the magnetic medium. The secondary and tertiary wires can now be wound inside the primary tube. For the proposed converter, the windings can be arranged as: the primary using a tube and the secondary and tertiary using twisted litz wires. With the coaxial winding techniques, the leakage inductance can be minimized. Hence external inductors should then be designed according to the desired amount of power flow.

\section{Control Strategy}

The control scheme aims to regulate the output voltage and the power of the primary source simultaneously by using the two phase shifts as control variables. An arbitrary power flow profile in the system can be achieved by phase shifting the three inverter stages as in the single-phase version [2]. The storage supplies/absorbs the transient power difference between the load and the primary source. Since the three-port converter can be viewed as a two-input two-output first-order system [9], the control system can be implemented with PI regulators based on the dual-PI-loop control strategy [7], one

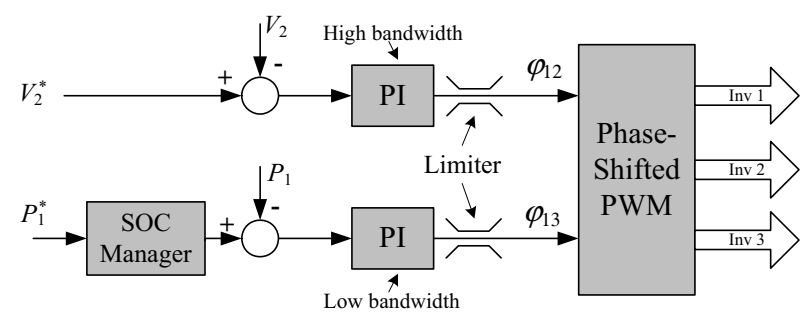

Fig. 10. Control scheme employing two PI compensators.

being employed to regulate the output voltage and the other controlling the power of the primary source, as illustrated in Fig. 10. Also incorporated in the control scheme is a state-ofcharge (SOC) manager for the storage [10].

The three-port converter can be modeled, using an averaging method, as three controlled dc current sources whose amplitudes are determined by the two phase shifts [9]. The current at each port $\left(i_{P 1}, i_{P 2}\right.$ and $i_{P 3}$, see Fig. 2$)$ can be averaged over one switching cycle, being a function of the two phase shifts. We can assume that the voltages at the ports are kept constant. Then the average current is the power divided by the port voltage. Thereby, the current source functions can be obtained. They are nonlinear functions of the two phase shifts and should be linearized at the operating point for a controloriented model [9].

The control variables are $\varphi_{12}$ and $\varphi_{13}$. Fig. 11 shows the small signal control loop block diagram of the TAB converter [9], where $G_{c 1}(s)$ and $G_{c 2}(s)$ are the transfer functions of the PI controllers. $G_{11}, G_{12}, G_{21}$ and $G_{22}$ are the small signal linearized gain of the converter, which can be derived from the power flow equations [9]. The block with gain "-1" is due to the definition of the direction of $i_{P 2}$ in Fig. 2. The block with gain " $V_{1}$ " is needed because the power is equal to the average current times the port voltage. $K_{M}$ is the gain of the phase shift modulator. $H_{1}(s)$ is transfer function of the load port formed by the filter capacitor $C_{2}$ and the equivalent load resistance $R_{L}$ :

$$
H_{1}(s)=\frac{R_{L}}{1+R_{L} C_{2} s}
$$

and $H_{2}(s)$ is the transfer function of the RC filter which filters out ac components in $i_{P 1}$ :

$$
H_{2}(s)=\frac{1}{1+\tau_{I} s}
$$

where $\tau_{I}$ is the time constant of the filter.

Not surprisingly, the two PI control loops are coupled and influence each other [15]. The bandwidth of the voltage control loop $\left(\varphi_{12}\right)$ is tuned higher (5 to 10 times higher) than that of the power control loop $\left(\varphi_{13}\right)$ so that the interaction is reduced while a fast response to the load variations is guaranteed. One can regard the former controller as the master while the latter is the slave.

A further improvement will employ a decoupling network, which eliminates the mutual effect, as also briefly discussed 


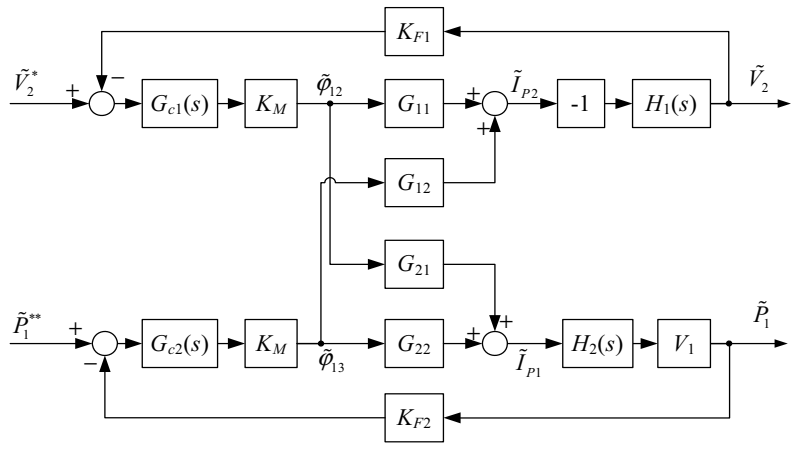

Fig. 11. Small signal control loop block diagram of the three-port TAB converter.

in [8]. In theory, the decoupling matrix $\mathbf{D}$ is the inverse of the small signal gain matrix $\mathbf{G}_{\mathbf{o}}$ of the converter:

$$
\mathbf{D}=\mathbf{G}_{\mathbf{o}}^{-\mathbf{1}}=\frac{1}{G_{11} G_{22}-G_{12} G_{21}}\left[\begin{array}{ll}
G_{22} & G_{12} \\
G_{21} & G_{11}
\end{array}\right] .
$$

Therefore, the total system gain matrix becomes diagonal and the interaction is eliminated, and the system can be controlled as two single-input single-output (SISO) systems:

$$
\left[\begin{array}{c}
\Delta I_{p 2} \\
\Delta I_{p 1}
\end{array}\right]=\mathbf{D G}_{\mathbf{o}}^{-1}\left[\begin{array}{c}
\Delta \varphi_{12} \\
\Delta \varphi_{13}
\end{array}\right]=\left[\begin{array}{c}
\Delta \varphi_{12} \\
\Delta \varphi_{13}
\end{array}\right]
$$

Notwithstanding its elegance, the decoupling network requires more computation power and needs real-time updating of the gain matrix $\mathbf{G}_{\mathbf{o}}$. It should also be noticed that the delay between the control/gating signals and the actual voltages applied to the transformer has to be taken into account because these affect the operating point (the actual phase shifts) which directly influences the gain matrix of the converter. Without this measure, the system cannot be satisfactorily decoupled.

\section{Vi. Simulation Results and Discussion}

To investigate the performance of the proposed topology, the converter and control scheme were simulated with PSIM7.0 under a variety of operating conditions. Table I gives a list of parameters used for simulation including the controller parameters. A standard voltage set, $48 \mathrm{~V}$ primary source, $48 \mathrm{~V}$ storage and $800 \mathrm{~V} \mathrm{dc}$ output, is assumed. Because of the high switching frequency $(100 \mathrm{kHz})$, high power $(10 \mathrm{~kW})$ and the low voltage $(48 \mathrm{~V})$, the required inductances are very small for the source and storage sides in this simulated case.

Suppose that the system is symmetrical; that is, all the inductances are equal when referred to the primary. Then the power rating of each port is identical. For the situation that the average power of the storage port over one switching cycle is zero, the phase shifts should obey $\varphi_{13}=0.5 \varphi_{12}$. Simulation results in Fig. 12 illustrate the operating waveforms of the converter, i.e., the voltages applied to the transformer and inductors network and the corresponding currents through the windings at $\varphi_{12}=\pi / 6$ and $\varphi_{13}=\pi / 3$. In this operating point the average power of the storage port equals zero. The current drawn from the primary source port $i_{P 1}$ (before filtering,
TABLE I

Simulation PARAmeters For the THREe-Port System

\begin{tabular}{|l|l|}
\hline Description & Symbol \& Value \\
\hline Primary source voltage & $V_{1}=48 \mathrm{~V} \mathrm{dc}$ \\
\hline Load side voltage & $V_{2}=800 \mathrm{~V} \mathrm{dc}$ \\
\hline Storage voltage & $V_{3}=48 \mathrm{~V} \mathrm{dc}$ \\
\hline Switching frequency & $f_{s}=100 \mathrm{kHz}$ \\
\hline Transformer turns ratio & $n_{2}=16.7, n_{3}=1$ \\
\hline Inductance & $L_{1 A}=L_{1 B}=L_{1 C}=0.05 \mu \mathrm{H}$ \\
\hline Inductance & $L_{2 A}=L_{2 B}=L_{2 C}=0.05 \mu \mathrm{H}$ \\
\hline Inductance & $L_{3 A}=L_{3 B}=L_{3 C}=14 \mu \mathrm{H}$ \\
\hline PI controller $G_{c 1}(s)$ & $K_{1}=1000, \tau_{1}=10 \mathrm{~ms}$ \\
\hline PI controller $G_{c 2}(s)$ & $K_{2}=0.2, \tau_{2}=10 \mathrm{~ms}$ \\
\hline LPF time constant $H_{2}(s)$ & $\tau_{I}=1 \mathrm{~ms}$ \\
\hline Phase shift modulator gain & $K_{M}=\pi / 500$ \\
\hline Feedback gain & $K_{F 1}=1$ \\
\hline Feedback gain & $K_{F 1}=1$ \\
\hline Nominal load resistance & $R_{L}=64 \Omega($ for $10 \mathrm{~kW})$ \\
\hline Output filter capacitor & $C_{L}=5000 \mu \mathrm{F}$ \\
\hline
\end{tabular}
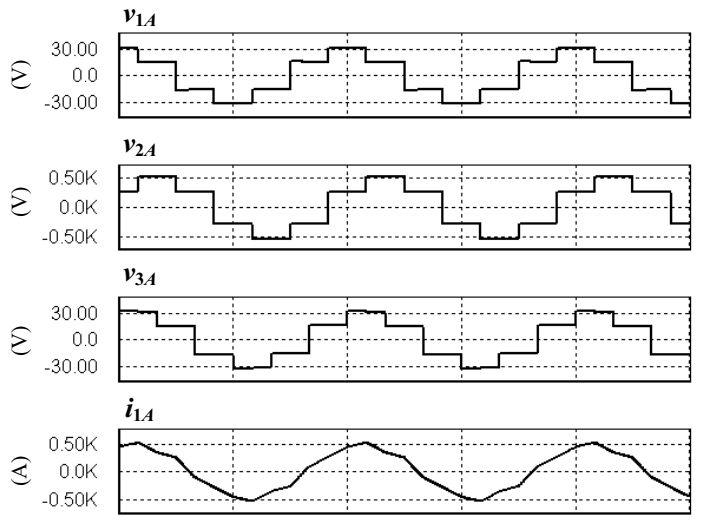
$i_{2 A}$
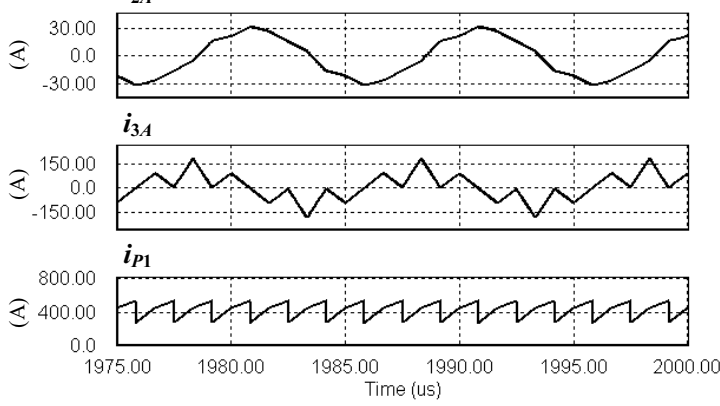

Fig. 12. Simulation results showing the voltages generated by the three-phase bridges and the currents through the transformer windings at $\varphi_{12}=\pi / 3$ and $\varphi_{13}=\pi / 6$ (phase A).

as indicated in Fig. 2) is also shown in the figure, being unidirectional, and the ripple is much reduced compared to the single-phase TAB converter.

Suppose that the power flow of the primary source is unidirectional, i.e., $P_{1}>0$ under all situations. The maximum power flow to the load port occurs when $\varphi_{12}=\pi / 2$ and $\varphi_{13}=0$. For this particular operating point, results from simulation are shown in Fig. 13. As can be seen, the currents are close to sinusoidal waves. 

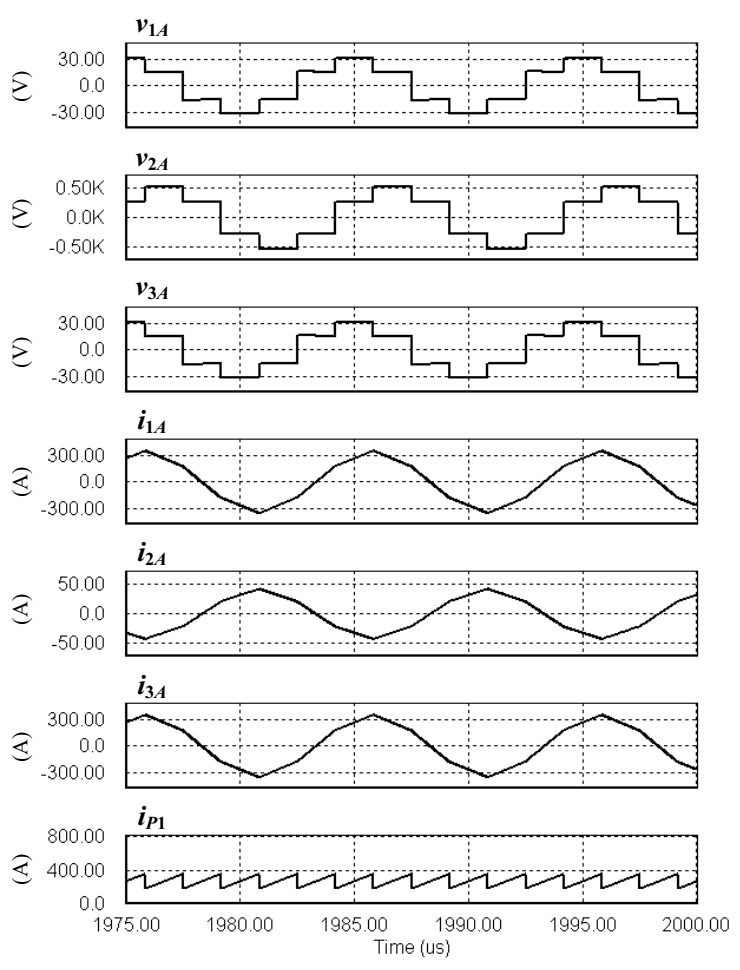

Fig. 13. Simulation results showing the voltages generated by the three-phase bridges and the currents through the transformer windings at $\varphi_{12}=\pi / 3$ and $\varphi_{13}=0$ (phase A).

Simulation results of the power flow control based on the dual-PI-loop control strategy are demonstrated in Fig. 14, where the load pulsates between $5 \mathrm{~kW}$ and $15 \mathrm{~kW}$ in a time interval of $10 \mathrm{~ms}$. The step changes in the load were simulated by suddenly adding/removing a resistor in parallel with the dc capacitor. As shown, the power supplied by the primary source $P_{1}$ remains at $10 \mathrm{~kW}$ - the average power consumed by the load, and the unmatched power between the source and load is supplied/absorbed by the storage.

Furthermore, Fig. 15 displays the response of the control system to an inverter-type load which draws sinusoidal current from the capacitor at the load port. The average power is again $10 \mathrm{~kW}$. It is evident that the control system is capable of regulating the output voltage and power of the primary source simultaneously. The amount of the ripple in $P_{1}$ is determined by the bandwidth of the control loop. The higher the bandwidth, the lower the ripple. In both of the simulated cases, the PI regulators are implemented as

$$
G_{c 1}(s)=K_{1} \frac{1+\tau_{1} s}{\tau_{1} s} \quad, \quad G_{c 2}(s)=K_{2} \frac{1+\tau_{2} s}{\tau_{2} s} .
$$

The controller parameters for simulation are listed in Table I.

Thus far, the single-phase version has been investigated using laboratory experimental setups at a rated power of $1 \mathrm{~kW}$ [7] and $3.5 \mathrm{~kW}$ [10]. It is intended to build a three-phase version prototype at $10 \mathrm{~kW}$ to further explore the idea.

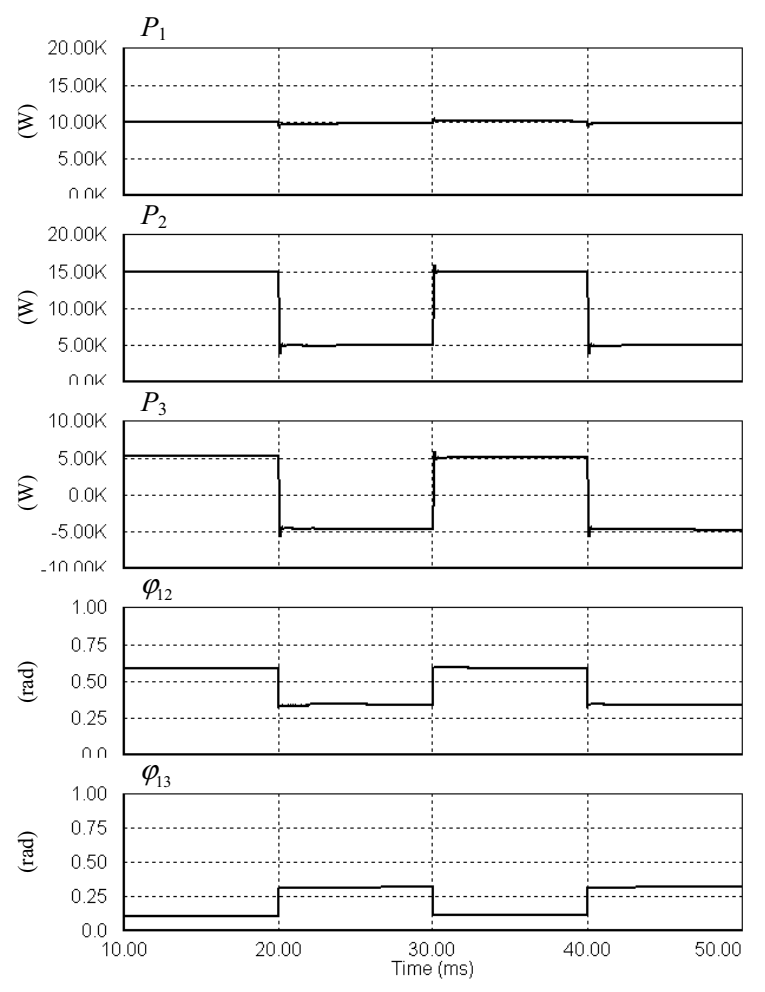

Fig. 14. Simulation results of power flow control with a pulsating load.

Due to the fact that the converter is symmetrical in threephase, the only possible control variable is the phase shift between the bridges. Therefore, other control methods such as duty ratio control to extend soft-switching region [7] can not be implemented in this topology straightforwardly. This converter will be soft-switched under the condition that all the dc voltages at the ports remain near constant. The converter suffers from a limited soft-switched operating region if one or more ports have a wide operating voltage.

\section{CONCLUSIONS}

In this paper, a high-power three-port three-phase bidirectional dc-dc converter has been proposed. The converter comprises a high-frequency three-port transformer and three inverter stages operating in a high-frequency six-step mode. The circuit interfaces a primary source and storage to a load and manages the power flow in the system. With the external leveling system the operation of the primary source can be optimized, for instance, operating it at a constant power. The converter provides galvanic isolation and supports bidirectional power flow for all the power ports. The advantage of the three-phase version compared to the single-phase one is the higher current handling capability and much lower current ripple at the $\mathrm{dc}$ side, thereby lower VA rating of filter capacitors owing to the interleaving effect of the threephase. The analysis of the topology and design issues of the transformer as both a conventionally and a coaxially wound 


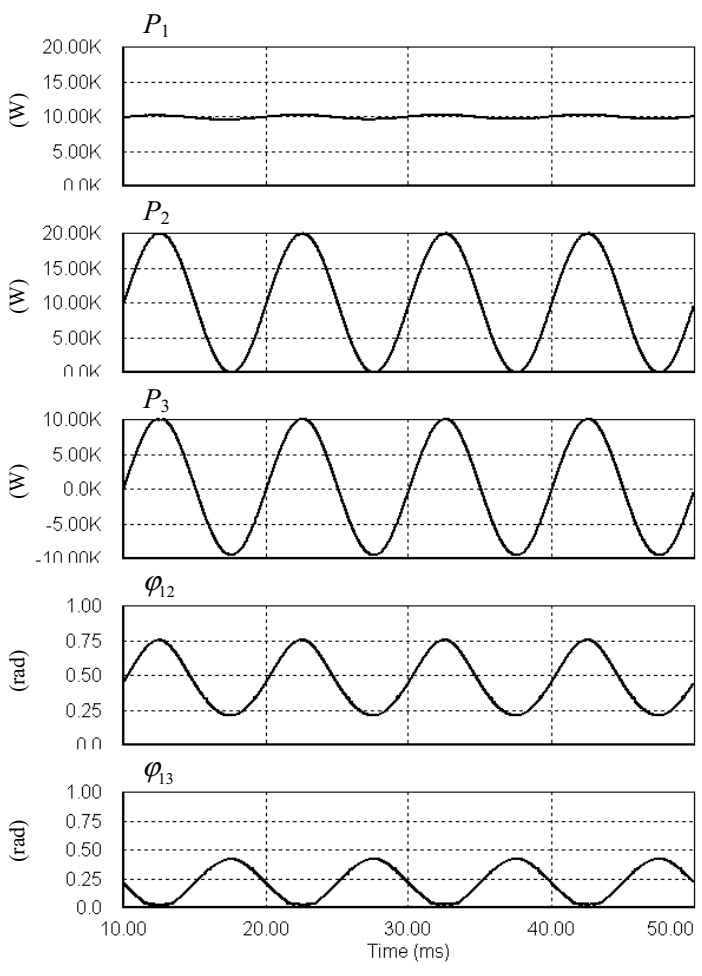

Fig. 15. Simulation results of power flow control with an inverter-type load.

structure were presented. Circuit simulation results under a variety of operating conditions have been provided, proving that the operating principle of the circuit and its dual-PI-loop control strategy are sound.

\section{REFERENCES}

[1] H. Tao, A. Kotsopoulos, J. L. Duarte, and M. A. M. Hendrix, "Family of multiport bidirectional DC-DC converters," IEE Proceeding Electric Power Applications, vol. 153, no. 3, pp. 451-458, May 2006.

[2] J. L. Duarte, M. Hendrix, and M. G. Simoes, "Three-port bidirectional converter for hybrid fuel cell systems," IEEE Trans. Power Electron., vol. 22, no. 2, pp. 480-487, Mar. 2007.
[3] H. Tao, A. Kotsopoulos, J. L. Duarte, and M. A. M. Hendrix, "Multiinput bidirectional DC-DC converter combining DC-link and magneticcoupling for fuel cell systems," in Proc. IEEE Industry Application Society Conference and Annual Meeting (IAS'05), Hong Kong,China, Oct. 2005, pp. 2021-2028.

[4] A. D. Napoli, F. Crescimbini, L. Solero, F. Caricchi, and F. G. Capponi, "Multiple-input DC-DC power converter for power-flow management in hybrid vehicles," in Proc. IEEE Industry Application Society Conference and Annual Meeting (IAS'02), Oct. 2002, pp. 1578-1585.

[5] D. Liu and H. Li, "A three-port three-phase DC-DC converter for hybrid low voltage fuel cell and ultracapacitor," in Proc. IEEE The 32nd Annual Conference of the IEEE Industrial Electronics Society (IECON'06), Paris, France, Nov. 2006, pp. 2558-2563.

[6] M. Michon, J. L. Duarte, M. Hendrix, and M. G. Simoes, "A threeport bi-directional converter for hybrid fuel cell systems," in Proc. IEEE Power Electronics Specialists Conference (PESC'04), Aachen, Germany, Jun. 2004, pp. 4736-4742.

[7] H. Tao, A. Kotsopoulos, J. L. Duarte, and M. A. M. Hendrix, "A soft-switched three-port bidirectional converter for fuel cell and supercapacitor applications," in Proc. IEEE Power Electronics Specialists Conference (PESC'05), Recife, Brazil, Jun. 2005, pp. 2487-2493.

[8] C. Zhao and J. W. Kolar, "A novel three-phase three-port UPS employing a single high-frequency isolation transformer," in Proc. IEEE Power Electronics Specialists Conference (PESC'04), Aachen, Germany, Jun. 2004, pp. 4135-4141.

[9] H. Tao, A. Kotsopoulos, J. L. Duarte, and M. A. M. Hendrix, "Transformer-coupled multiport ZVS bidirectional DC-DC converter with wide input range," IEEE Trans. Power Electron., to be published.

[10] H. Tao, J. L. Duarte, and M. A. M. Hendrix, "High-resolution phase shift and digital implementation of a fuel cell powered UPS system," in Proc. 12th European Conference on Power Electronics and Applications (EPE'07), Aalborg, Denmark, Sep. 2007, pp. 1-10.

[11] R. W. DeDoncker, D. M. Divan, and M. H. Kheraluwala, "A threephase soft-switched high-power-density DC/DC converter for highpower applications," IEEE Trans. Ind. Appl., vol. 27, no. 1, pp. 63-73, Jan./Feb. 1991

[12] M. H. Kheraluwala, D. W. Novotny, and D. M. Divan, "Coaxially wound transformers for high-power high-frequency applications," IEEE Trans. Power Electron., vol. 7, no. 1, pp. 54-62, Jan. 1992.

[13] M. S. Rauls, D. W. Novotny, and D. M. Divan, "Design considerations for high-frequency coaxial winding power transformers," IEEE Trans. Ind. Appl., vol. 29, no. 2, pp. 375-381, Mar./Apr. 1993.

[14] M. S. Rauls, D. W. Novotny, D. M. Divan, R. R. Bacon, and R. W. Gascoigne, "Multiturn high-frequency coaxial winding power transformers," IEEE Trans. Ind. Appl., vol. 31, no. 1, pp. 112-118, Jan./Feb. 1995.

[15] H. Tao, A. Kotsopoulos, J. L. Duarte, and M. A. M. Hendrix, "Design of a soft-switched three-port converter with DSP control for power flow management in hybrid fuel cell systems," in Proc. 11th European Conference on Power Electronics and Applications (EPE'05), Dresden, Germany, Sep. 2005, pp. 1-10. 